Praxis, Vol. 14, No. 2, 109 - 111

DOI: http://dx.doi.org/10.21676/23897856.2913

\title{
EDITORIAL
}

\section{Del sentido reflexivo y formativo: un aporte a la evaluación con carácter diagnóstico formativo ECDF}

\author{
Jorge Mario Ortega Iglesias'
}

\begin{abstract}
Q e aproxima un momento crucial para cientos de maestros en el territorio nacional, el cual tiene - que ver con la evaluación para ascenso de grado y reubicación de nivel salarial de los docentes que fueron nombrados bajo el Decreto Ley 1278 del 2002. Este proceso desde el año 2015 contempla como principio de realización y desarrollo un carácter diagnóstico formativo. La Evaluación con Carácter Diagnóstico Formativo (ECDF), como bien se conoce en el gremio profesoral, significa en muchos casos una esperanzadora oportunidad de ascender en el escalafón docente para mejorar las condiciones salariales, y con ello, avanzar hacia la anhelada "dignificación" de la profesión docente. Por lo anterior, su adecuada realización se ha constituido en un momento de suma importancia para la vida profesional de los maestros en el territorio colombiano.
\end{abstract}

La Resolución 22453 del 2 de diciembre del 2016, define la ECDF como

un proceso de reflexión e indagación, orientado a identificar en su conjunto las condiciones, aciertos y las necesidades en que se realiza el trabajo de los docentes, directivos docentes, directivos sindicales, docentes tutores y orientadores, con el objeto de incidir positivamente en la transformación de su práctica educativa pedagógica, directiva o sindical; su mejoramiento continuo, sus condiciones, y favorecer los avances en los procesos pedagógicos y educativos en el establecimiento educativo (p.4).

Tal definición incorporó un cambio de perspectiva evaluativa orientada hacia un enfoque cualitativo, particularmente en la metodología de aplicación de este dispositivo de evaluación. Este ajuste privilegia la labor del educador en su cotidianidad de aula bajo un ambiente natural, teniendo en cuenta las características y condiciones del contexto donde este trabaja, así como su interacción con los diferentes actores y la comunidad escolar. En consecuencia, la ECDF trajo consigo un giro determinante en los procesos de evaluación del profesorado, los cuales pasaron de entenderse como una prueba escrita de poco alcance para la realidad vivencial de los docentes, hacia una comprensión alternativa fundamentada en procesos de reflexión y mejoramiento continuo producto de las experiencias de ser maestro en las prácticas de aula cotidianas. Sin embargo, este giro también ha traído consigo interesantes cuestionamientos alrededor de la aplicación de la ECDF, pues si bien, existe la determinación de precisar su carácter diagnóstico, el hecho reflexivo - y por naturaleza formativo-, sigue siendo de poco alcance, por lo menos, en su implementación.

${ }^{1}$ Editor. Universidad del Magdalena, Santa Marta, Colombia. Correo electrónico: jortegai@unimagdalena.edu.co ORCID: 0000-00026458-3650 
Dado este breve panorama, se presentan algunos planteamientos que indagan con mayor profundidad por el sentido reflexivo y formativo de esta evaluación, no a manera de explicitar un deber ser que determine un posicionamiento que sea necesario seguir, sino más bien como una lectura dialógica que aporte elementos constructivos en este importante proceso, del cual, insisto, es necesario destacar y desarrollar con empeño su aspecto reflexivo y, por ende, formativo.

Los planteamientos que se van a desarrollar parten de dos cuestionamientos fundamentales: en el primero se indaga sobre cómo es el proceso de reflexión que llevan a cabo los maestros a partir de la realización de la ECDF; y en el segundo, más con una intención propositiva, se pregunta cómo la ECDF se convierte en una herramienta pedagógica potencializadora de procesos de desarrollo profesional del profesorado que la realiza. En estas cortas líneas no se pretende dar un debate profundo sobre el sentido reflexivo y formativo de la ECDF; somos conscientes de que existen muchos otros elementos críticos de esta evaluación que no se desarrollan en este apartado y que son de interés general. No obstante, se tiene la firme intención de hacer un llamado a toda la comunidad educativa para visibilizar aspectos de esta evaluación que bien podrían configurarse como una real y auténtica estrategia de crecimiento y desarrollo profesional de los maestros en nuestras escuelas.

Preguntarse sobre los procesos de reflexión de los maestros, en el marco de un proceso evaluativo, implica necesariamente un serio esfuerzo intelectual que supone repensar y analizar con detenimiento la actuación del profesorado en determinado momento del hecho educativo. El conocimiento producto de una práctica reflexiva y reflexionada (Schön, 1992; De Vicente Rodríguez, 1999) representa un valor agregado invaluable, lleno de criterio, contexto, localidad y participación activa del sujeto que la realiza, por lo que su empoderamiento y puesta en escena para transformar su quehacer, debe estar suscrita no solo a instrumentos evaluativos carentes de socialización, análisis y reconocimiento, sino también al diseño de estrategias que involucren a la comunidad educativa participante en el ejercicio profesional del profesor.

En este sentido, la reflexión de la práctica que por naturaleza suscita un aspecto formativo en la ECDF merece un lugar de mayor complejidad, asumiéndose como una constante oportunidad de mejora que implica la participación de distintos actores, quienes también han hecho posible que los maestros perfeccionen y valoren su práctica cotidiana. La reflexión en tal caso, y más como dispositivo de evaluación, ha de superar prácticas situadas en un solipsismo pedagógico, que limitan el grado de profundidad y rigor de la reflexión del maestro. En suma, la reflexión de la cual es objeto de evaluación el profesor requiere un lugar de mayor apertura y consolidación; debería desarrollarse en el marco de una comunidad que aprende y crece de manera colectiva.

De este modo, la reflexión, en caso de la ECDF, sugiere un desarrollo provocado, suscitado y de intercambio con el ente evaluador, puesto que el acto mismo de reflexionar sobre la práctica convoca la participación de diferentes actores que hagan posible y efectivo un proceso de indagación $y$ transformación coherente con dicha práctica.

Otro aspecto en el cual conviene profundizar y que guarda estrecha relación con sentido formativo de la ECDF tiene que ver con las posibilidades de desarrollo profesional que este ejercicio promueve. Si bien es claro que el carácter diagnóstico queda en evidencia durante el proceso de implementación de esta evaluación, dado que arroja una "radiografía" sobre el desempeño 
del profesor a partir de unos criterios evaluativos previamente definidos (contexto de la práctica, reflexión y planeación de la práctica, praxis pedagógica y ambiente de aula), los resultados y su trabajo tanto de divulgación como de socialización pueden ser reorientados de manera pertinente hacia una propuesta de desarrollo profesional docente. En este orden de ideas, los resultados de la ECDF de cada profesor constituyen un insumo clave que permite reconocer, entre otros elementos, las necesidades puntuales de índole formativa que requiere este profesorado (Imbernón, 1999). Así las instituciones educativas, en conjunto con las entidades territoriales, tienen en los resultados de esta evaluación una fuente primaria sobre las necesidades y requerimientos formativos de los maestros.

Las posibilidades de desarrollo profesional del profesorado merecen ser diseñadas teniendo en cuenta las necesidades evidentes en su ejercicio profesoral. Así pues, el diseño y aplicación de la ECDF permiten que se generen los insumos apropiados para que, a partir de los resultados que arroja esta evaluación, se configuren ejercicios de formación locales, situados y contextualizados, en donde los maestros puedan ser protagonistas de su propio desarrollo, dado que los contenidos de formación podrían identificarse a partir de dicho examen.

Teniendo consciencia de que son numerosos los retos que la ECDF ha dejado a partir de su implementación, conviene adelantar diferentes estudios que visibilicen sus dificultades, fortalezas y demás oportunidades de mejora. Con ello se podría intentar la configuración de un auténtico dispositivo de evaluación del profesorado que, más allá de figurar en el imaginario colectivo como una suerte de filtro presupuestal, represente una robusta oportunidad de mejora y cambio.

\section{Referencias bibliográficas}

Decreto 1278 (2002). Por el cual se expide el Estatuto de Profesionalización Docente. Diario Oficial $N .^{\circ}$ 44840, 2002, 20 de junio. Recuperado de http://www.suin-juriscol.gov.co/viewDocument. asp?ruta $=$ Decretos $/ 1257729$

De Vicente Rodríguez, P. (1999). La formación del profesorado como práctica reflexiva. En L. Villar. (coord.), Un ciclo de enseñanza reflexiva. Estrategia para el diseño curricular (pp. 53-88). Bilbao: Ediciones Mensajero.

Imbernón, F. (1999). La formación y el desarrollo profesional del profesorado. Barcelona: GRAO.

Resolución 22453 (2016). Por la cual se establecen las reglas y la estructura de actividades para el proceso de evaluación que tratan los artículos 35 y 36 (numeral $2^{\circ}$ ) del Decreto Ley 1278 de 2002 para el ascenso de grado o la reubicación nivel salarial de los educadores oficiales regidos por dicha norma, y se dictan otras disposiciones, MEN, 2016, 02 de diciembre. Recuperado de https://www. mineducacion.gov.co/1759/articles-358693_ recurso_1.pdf

Schön, D. A. (1992). La formación de profesionales reflexivos. Hacia un nuevo diseño de la enseñanza y el aprendizaje de las profesiones. Barcelona: Paidós. 